\title{
Success factors for the development of process technology in process industry Part 1: a classification system for success factors and a rating of success factors on a tactical level
}

\author{
Thomas Lager* \\ Centre for Management of Innovation and Technology \\ in Process Industry, Luleå University of Technology, \\ SE-97187 Luleå, Sweden \\ E-mail: thomas.lager@ies.luth.se \\ ${ }^{*}$ Corresponding author

\section{Sven-Åke Hörte} \\ Department of Business Administration \\ and Social Sciences, Division of Industrial Organization, \\ Luleå University of Technology, SE-97187 Luleå, Sweden \\ E-mail: sven-ake.horte@set.hh.se
}

\begin{abstract}
In a research project on the development of process technology in process industry, success factors have been developed and ranked by R\&D managers in various sectors of the European process industry. The results are presented in two parts, of which this is Part 1. As an introduction to this part, a new classification system for success factors in $R \& D$ is developed and the final discussion in Part 2 presents a model for company implementation. The empirical results stress the importance of good technology transfer in the process development process. The results can also be seen as a shopping list and a starting point for in-company development of success factors and performance indicators for process development.
\end{abstract}

Keywords: process industry; process technology; process development; success factors.

Reference to this paper should be made as follows: Lager, T. and Hörte, S- $\AA$. (2005) 'Success factors for the development of process technology in process industry Part 1: a classification system for success factors and a rating of success factors on a tactical level', Int. J. Process Management and Benchmarking, Vol. 1, No. 1, pp.82-103.

Biographical notes: Thomas Lager is an adjunct professor and director of the Centre for Management of Innovation and Technology in Process Industry (PROMOTe) at the Luleå University of Technology in Sweden. He is president of B\&L Innovation, a consulting firm specialising in R\&D Management. He holds an MS degree in Mining Engineering from the Royal Institute of Technology, Sweden, a PhD in Mineral Processing and a PhD in Business Administration and Economics from the Luleå University of Technology, Luleå. Lager has also served 15 years in the process industry, mainly in the capacities of Production Engineer and R\&D Manager. 
Sven Åke Hörte is a professor in Industrial Organisation in the Department of Business Administration and Social Sciences at the Luleå University of Technology and Professor in Sociology at Halmstad University. He holds a $\mathrm{PhD}$ in Sociology from Gothenburg University and an Associate Professorship in Operations Management at Chalmers University of Technology. He is a fellow of Faculty of the Institute of Management of Innovation and Technology.

\section{How do we improve the development of process technology in process industry?}

Industrial product development skills and the performance of new product development have been in focus during the past decade, not only in companies manufacturing assembled products but also in the process industry. In all manufacturing industry the relation between price and performance of new and improved products highlights the complex situation a developer always faces: a good product is often a successful compromise between performance and price. Price and profit margins relate directly to manufacturing cost, which in the long run is influenced by the company's ability to develop cost-efficient process technology. The question of how to improve the development of process technology and what we here call the 'process development process' is the subject of a larger research project on the development of process technology in the process industry. In this part of the study, the aim is to develop potential success factors for process development and to test their importance in different sectors of process industry. Before we go into the empirical research results, let us start with a discussion of some important concepts often used in this context.

\subsection{Best practice, success factors and performance indicators: where do we start?}

These terms are widely used in both academic circles and the industrial world, but their meanings are seldom well-defined. Developing success factors and measuring $R \& D$ performance are important issues for management of $R \& D$, and there have consequently been a large number of publications in this area over the past two decades. A comprehensive literature survey found more than 90 papers [1]. Measuring R\&D performance or productivity is not very useful for company R\&D management unless it gives an understanding of how well one is doing and how one could do better [2]. This underlines the importance of relating measurement of $R \& D$ performance to $R \& D$ success factors. Some studies advocate a focus on R\&D behaviour and success factors, while others stress the importance of output performance measures [3]. The answer is more likely that the two activities complement each other in an efficient process of total performance improvement for $R \& D$.

\subsubsection{Best practice today, bad practice tomorrow?}

The second word in the term 'best practice' implies some sort of behaviour in the sense of 'habitual or customary performance' [4]. We then add the word 'best' and imply that 
there is some sort of practice that is superior to other practices, evidently not only better, but the best. Using 'science and best practice' is sometimes a recommendation for good professional behaviour, and best practice is then associated with behaviour that has proven successful over a longer period of time [5]. The term 'best practice' is rather close to the concept of 'success factors', which will be discussed in the following section. The wording of both terms carries a risk, however, in that they can be interpreted to mean that a best practice for something is of an everlasting nature. The time aspect of best practice and success factors will be further discussed in Part 2 of this study, but history often tells us that a given kind of behaviour, and success related to that behaviour, is not likely to stay the same indefinitely: what is best practice today may be bad practice tomorrow.

\title{
1.1.2 Good behaviour or best practice condensed into a number of success factors
}

Good behaviour and best practice can be condensed into a number of well-defined success factors.

We may first of all however ask the fundamental question whether it is possible to find 'success factors' at all, and secondly whether the concept is useful for performance improvements in industry. The answer must be of a more philosophical nature, related to the overall question of whether it is possible at all to find good practice in general and good management practice in particular. In the authors' opinion it is similar to the question of whether it is possible to find good working practice for carpenters making furniture or for farmers in agricultural work, where the answer is yes. It is however important to bear in mind the contextual and time dependence of best practice and success factors: making furniture for IKEA, for example, does not call for the same type of best practice as making 18th century cabinets. If we then assume that it is possible to find best practice and success factors, do we need the concepts? In the authors' opinion, the answer is yes! Before we start the discussion of performance indicators and performance measures, we must define what we want to improve and measure. Building a company system for performance measurement without a prior clarification of what we would like to improve is probably a fairly pointless exercise. In this study the following definition was presented to the respondents:

\begin{abstract}
"In this context, we define 'success factors' in process development work as specific working methods and practices that lead to successful development projects (often called 'Best Practice' projects). The measure of success in development work and individual development projects may of course vary. In your assessment of the following potential success factors we would like you first to consider the importance of the selected success factor to future pay-back from the development, and then the importance of completing development on time at acceptable cost and meeting specified functional and quality criteria. Whether all these criteria for success need to be satisfied, or only some of them, naturally depends on the nature of the process development work."
\end{abstract}

In what follows here all factors that are or could be related to success are called 'success factors'. The degree of uncertainty, or how well they are proven, is sometimes expressed by the prefix 'candidate' or 'potential' for not proven, and 'critical' for success factors that are well proven. 


\subsubsection{Company performance improvements, measured by performance indicators}

Once relevant success factors have been identified, they must be implemented in the company's work processes and daily life before performance can be improved. After implementation, and preferably even before implementation, the performance that relates to those success factors should be measured. Lacking a good system for performance measurement and feedback, any improvement system is likely to fail [6]. The development of performance indicators for success factors for process development will be further discussed in Part 2 of this study.

\subsection{Success factors for process development: a study presented in two parts}

In an exploratory survey of R\&D managers in European process industry, success factors for process development were rated and ranked as a part of a larger research project on the development of process technology in process industry. In this paper, Part 1 of the study, we begin with the development of a classification system for success factors for R\&D. Using this classification system, success factors for process development were developed during interviews with $\mathrm{R} \& \mathrm{D}$ managers from various sectors of process industry. The success factors were later structured on different hierarchic levels. Three levels have been selected: a strategic level, a tactical level and an operational level. This paper presents the results of the development of success factors on a tactical level and their rating by $R \& D$ managers.

A forthcoming paper, which forms Part 2 of this study, will present the results from ranking of success factors on an underlying more explanatory operational level, and the results will be used to translate success factors into performance indicators using QFD methodology.

\section{Success factors for what and for whom? Development of a classification system and typology of success factors for $R \& D$}

In Section 1 it was argued that we do need success factors and that we should start by clarifying what we want to improve before proceeding to develop performance indicators. However, we have not yet discussed in depth whether it is possible to find generic success factors or, looking at it from the opposite angle, the degree of specificity of success factors. The complexity of company life, and especially the work of the R\&D department, makes it important to consider the contextual dependence of success factors. Results from the Product Development Management Association (PDMA) success measurement project for product development indicate not only that product development success should be measured on two levels (project level and company level), but that the criteria selected should depend on what type of product development projects are carried out [7]. In a survey of publications on factors for success in R\&D projects and new product innovation, the conclusion is that there are an abundant number of success factors for R\&D presented in literature, but which of these are relevant to different development contexts is certainly not clear, and the notion of finding success factors of general applicability to R\&D is considered naive [8]. The need for a better classification system for success factors is noted in other studies, and an embryo for such a classification has 
also been outlined by Lager and Hörte [9]. In the following text this classification system is further developed into a general system for the classification of success factors for R\&D. The proposed classification system that will be referred to in what follows is presented below in Table 1.

Table 1 A classification system for success factors for research and technical development. Success factors have first of all been organised in a hierarchic structure on two levels (the operational level of success factors is not included). Task specificity is the main dimension for classification, but success factors could also be classified in the dimension organisational specificity. The importance rating of individual success factors on a tactical level (S.F. No) is tentatively illustrated with figures on a 9-point scale in the columns for task specificity

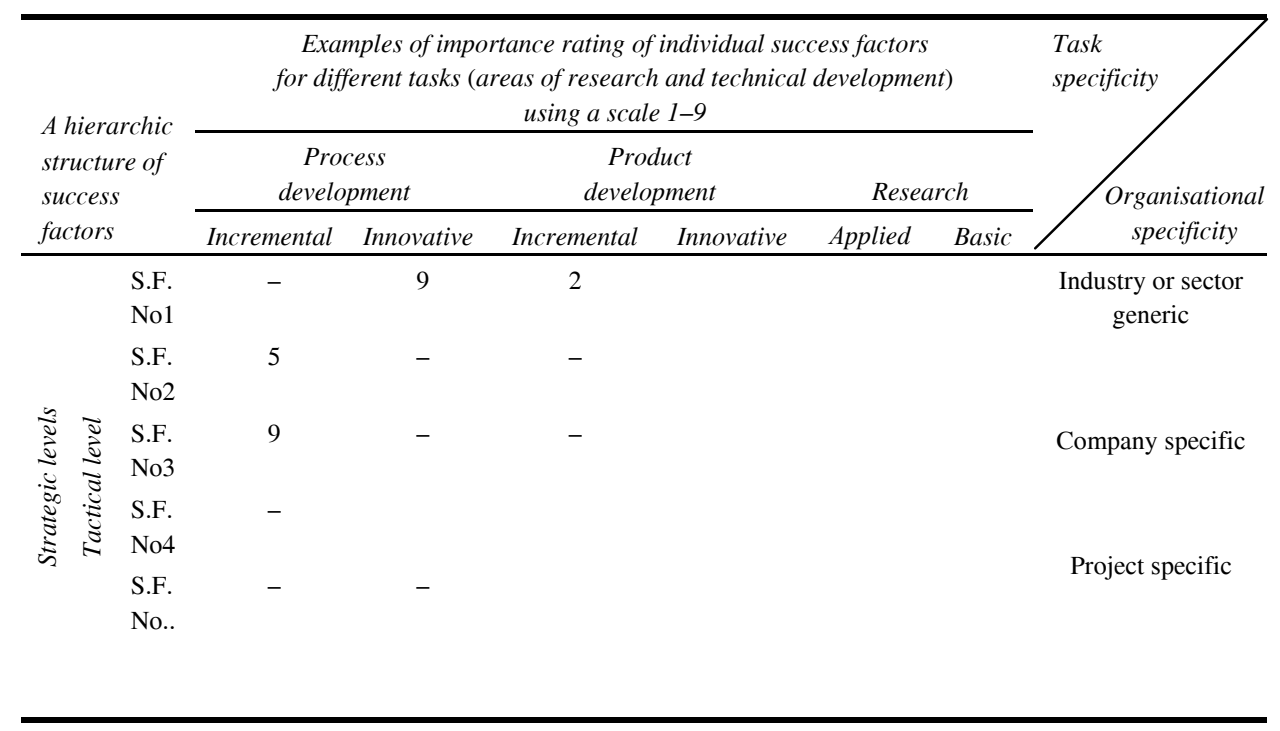

\subsection{Success factors on different hierarchic levels}

Various kinds of affinity techniques are often used in the development methodology known as Quality Function Deployment (QFD) to build hierarchic structures of customer demands or product properties [10]. In the QFD methodology, the different customer needs are usually developed in a hierarchic structure with at least three levels. Using the QFD vocabulary for product development and customer needs with regard to a product, the primary level is often called a 'strategic level', the secondary level a 'tactical level' and the tertiary level an 'operational level' see further [11], for example. The denominations are thus not related to company strategic and tactical behaviour, but represent a differentiation of levels of importance and strategic intent for different levels of success factors. This is further illustrated in Figure 1 below, where the success factors with bold frames show how individual success factors on a higher level can be developed further into a number of more explanatory success factors on underlying levels. 
Figure 1 Success factors on different hierarchic levels. Success factors with bold frames show how individual success factors on a higher level can be developed further into a number of more explanatory success factors on underlying levels. The operational level (also called root level) is to be used in the further development of performance indicators

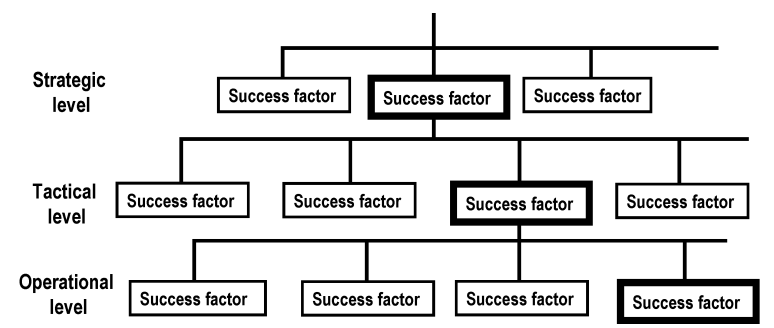

Let us use an example to illustrate this methodology and how it could be applied to the development of success factors. Assume that a success factor on an R\&D strategic level is 'good project management'. For industry professionals this is evident, and it will be of more interest if this strategic success factor can be developed further. One underlying success factor for 'good project management' may be 'an ability to form good project teams', but it will be even more interesting for an industry professional if this underlying success factor is developed even further. An underlying operational success factor may in this case be 'building teams with different personalities'. Such an operational success factor can give better guidance on how to improve the performance and to develop measurable performance indicators. A hierarchic structure of success factors on two levels was illustrated in Table 1.

\subsection{Success factors for different tasks: success factors for what?}

The contextual dependence of success factors relates to the type of company activity to which the success factors are relevant. We could tentatively classify the activities of the $\mathrm{R} \& \mathrm{D}$ department into the areas of product development, process development and research.

Further categorisation of those activities should depend on the type of company $\mathrm{R} \& \mathrm{D}$, but it is suggested that the activities should be categorised on a lower level, for example differentiating between a more incremental type of development and development of a more innovative nature [9]. In Table 1 the task specificity is shown at the top of the table and the relevance of individual success factors to different areas of $\mathrm{R} \& \mathrm{D}$ is given by an importance rating. A success factor with high relevance has been given the highest rating (9) in the column for innovative process development, while a success factor with no relevance to incremental product development has been given no mark at all.

\subsection{Success factors on different organisational levels: success factors for whom?}

It is reasonable to assume that different success factors are more or less company-specific, so from a company perspective the question may be expressed as: "To what extent are certain success factors from other studies relevant to my company?" 
Following this line of thought, there may be success factors that are not trivial, that are valid not only on company or sectorial level but even for all types of manufacturing industry. Nordhaug's classification distinguishes two organisational levels: industry level and company level [12]. Because of the diversity of projects in a company, there is possibly also a need for a project level. Success factors on an industry level are then success factors that are not company-specific but could be of use for many different types of companies in different sectors of industry. It would thus be of particular interest to identify such success factors and draw the attention of industry to them. Company-specific success factors are no less important, but they must be developed within the organisation. Finally, project-specific success factors must be considered in each individual project, since it is likely that every project has certain specific circumstances that are unique. In Table 1 the organisational specificity is illustrated to the right and success factors can be classified into those three different categories but should not necessarily be structured in this dimension.

\section{Development of a contextual model for the process development process and classification of success factors for process development on a strategic level}

In the development of success factors for process development some sort of structural backbone or model is needed. Such a structure can also be used in the further classification of success factors for process development on a strategic level, previously presented in Figure 1.

\subsection{The process development process in process industry}

In the development of new or improved products in manufacturing industry a company needs a more or less formal work process - a 'product development process', see [13], for example. For the development of process technology in process industry there is also a need for a more or less formal work process - a 'process development process'. Such a process development process may of course have different form and content in different companies; one simplified structural model is presented in Figure 2 [14].

Figure 2 A simplified structural model of the process development process in process industry. Only the three main phases have been illustrated [14]

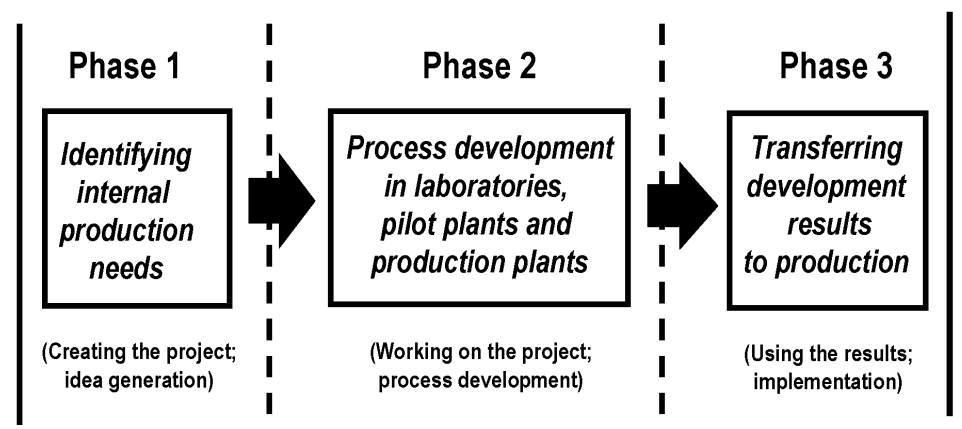


Identifying the needs of internal production is an activity that could probably be developed into a more systematic process, by analogy with the identification of external customer needs. Once the company development needs have been identified, the necessary idea generation can start. There are many potential sources of innovation, a subject treated extensively by von Hippel [15].

Sources of technical innovation for a Chemical Industry are discussed by Hutcheson et al., who emphasise how important it is for $\mathrm{R} \& \mathrm{D}$ in process industry to collaborate with external industry like process contractors, equipment manufacturers and raw material suppliers $[16,17]$. Freeman lists fifteen possible sources of new technology, of which in-house R\&D is only one [18]. Freeman further reflects, however, that

"the most successful and innovative firms have been characterised by a strong in-house capability for $\mathrm{R} \& \mathrm{D}$, generating a corporate research tradition and firm-specific processes of technology accumulation" [18].

Enos points out that in many cases innovations in the petroleum refining industry came from people outside the industry but often closely related to it [19]. Identification of internal production needs is an important task in the company development of process technology, but so is discovering the means to fulfil those needs.

The second phase of the process development process is the phase where the real development work takes place in the laboratory and pilot plant. There are three options for acquiring new process technology: develop new technology within the internal organisation (which this study focuses on); acquire new technology from external organisations; or a combination of both in a joint development. The second option, which shortcuts the total development process, using external sources, covers two essentially different cases: the new technology already exists and can be acquired by licensing or purchase; the new technology must be developed within the external organisation. This type of external technology transfer has been widely studied, see [20] for example; it shortcuts the total process insofar as the development phase is non-existent or small. The first option is when the new or improved process technology is developed mainly 'in-house'.

For internal transfer of technology, which is far less studied than external transfer, the internal technology transfer phase is the important link between new process technology and production, just as development of new products is of little use without a successful product launch on the market. The results of a study of developer-user interaction and user satisfaction in internal technology transfer show a rather complex picture of how to obtain a smooth transfer process [21]. For both types of technology transfer there may be barriers of different kinds that prevent an efficient transfer of technology. Those barriers are not only based on and related to the transferability of the technology, but may often be of a more cultural or social character and related to communication between the supplier and the customer. The difficulties associated with technology transfer in Petroleum Industry have been related to the discrepancy between the innovative individuals, often with a good theoretical background, and the production people focusing on proven trouble-free technology [22]. The personal aspect of technology transfer is also highlighted in a paper by Langrish, where the conclusion is that the most efficient transfer process is the transfer of the person with the specific knowledge [23]. 


\subsection{A contextual model of the process development process}

In the preceding discussion of the process development process it is argued that this process is by no means an internal company matter, and certainly not an internal R\&D matter. The sources of ideas for process development are in many cases external, and the development work itself is often carried out in association with external organisations. The conclusion is that the process development process as such is strongly affected by both the internal and external environments. The process development process thus takes place in a specific internal company environment surrounded by the company's external competitive business environment. This is illustrated in Figure 3, where the previously presented model of the process development process has been put in context.

Figure 3 A simplified contextual model of the process development process. The model presented in Figure 2 has been put here in the context of the company's internal and external environment

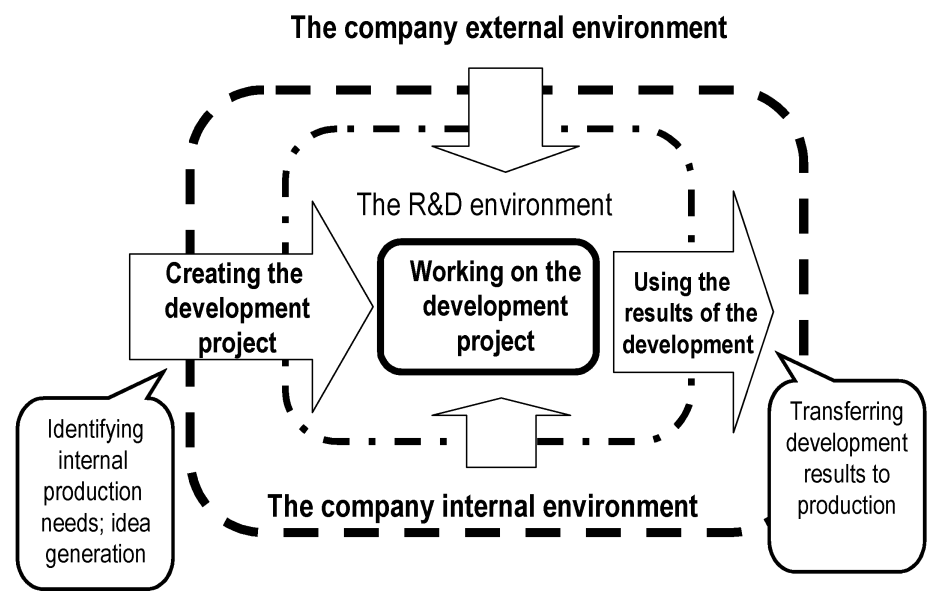

It has been observed that the internal and external development environments are gradually merging and that the network of internal performers is interlocked with external players [24]. The focus on the internal customer must not however be emphasised to the extent that the external customer for the final product is totally neglected. In that respect there should always be an interaction between the process and product development processes [14]. This contextual model of the process development process will be used as an overall structure of success factors for process development on a strategic level in the study and in the presentation of the research results.

\section{A survey of R\&D managers in European process industry}

\subsection{Research strategy and approach}

There are two alternative approaches to develop a list of potential (candidate) success factors. One approach is to scavenge existing published material in the field and to use previously presented potential or proposed success factors. The other approach is to go out and listen to industry professionals in interviews. 
In the area of product development there are many studies that present interesting potential success factors, but such is not the case for process development. This study therefore started with interviews with eight $R \& D$ managers from different sectors of process industry to obtain a list of potential success factors. In the process of further establishing whether these potential success factors really are factors that will lead to success, there are also two alternative approaches. One approach is to ask respondents in industry how they behave and try to correlate this with how successful their behaviour is, either by a direct measure of the performance or asking the respondent to estimate success. The difficulties with this approach will be further discussed in Part 2, but it can already be stated that a major drawback is the difficulty of getting good objective measures of internal company behaviour. The alternative approach, which was the one selected in this study, is to ask the R\&D managers to be the judges of a number of potential success factors, using their intimate knowledge of their own R\&D. The advantage of asking the respondents to rate potential success factors is that the results may be of a more prescriptive nature, since the respondents are not stating how things are at present, but how they would like them to be.

\subsection{Development of potential success factors}

The interviews were carried out in an interactive fashion and the respondents had previously been asked to select two completed process development projects, one 'successful' and one 'not so successful'. The respondents were asked to describe the two projects, and to try and pinpoint factors of importance for their outcome. After the interviews all potential success factors were written down on post-it and were structured in clusters using an affinity technique. A three-level hierarchy of potential success factors was created as a platform for the development of a questionnaire about success factors for process development. The strategic level was categorised in the five areas from the previously presented contextual model of the process development process, Figure 3:

- creating the development project

- $\quad$ working on the development project

- using the results

- internal environment

- external environment.

The secondary tactical level was selected, including 25 potential success factors, with a view to presenting a manageable number of success factors for importance rating in the questionnaire. The underlying, more explanatory, tertiary operational level of success factors was included for ranking. Those results will be presented in Part 2 of this study, and will be used in the development of performance indicators.

\subsection{Survey and rating of the candidate success factors by the respondents}

The potential success factors were included in a questionnaire that was sent out to R\&D managers in the European process industry. The companies have been categorised as mining and mineral industry, food and beverage industry, pulp and paper industry, chemical industry, basic metal industry, and other process industry (see further 
Appendix 1). The sample and the survey are further presented in Appendix 2. The success factors on a tactical level were presented to the respondents accompanied by the following wording:

\begin{abstract}
"In the following text we propose a number of potential success factors for process development; they are based on the results of interviews with the R\&D managements of eight leading industrial organisations from different sectors of Nordic process industry. Of the 25 proposed success factors, some are likely to have influence on all types of development work (including process development), while others are probably applicable only to process development. We now ask you to weight all potential success factors, indicating what is important and not important according to your experience of process development work. Please grade success factors according to the following scale: $1=$ Not important; $2=$ Of minor importance, $3=$ Important; $4=$ Very important; $5=$ Decisive to success. Indicate the degree of importance by circling the figure you select."
\end{abstract}

\title{
4.4 Treatment of the research results
}

The number of 5 ratings given by all respondents for each success factor was first calculated. In the text above, the meaning of a 5 was explained to the respondents as 'decisive to success', and consequently it can be argued that if a respondent gives a potential success factor a score of 5 , it is by definition a success factor for them. Adding all 5's for each success factor and afterwards ranking the success factors by the total number of 5's they received was the first calculation made with the 25 individual success factors. The arithmetic mean of all respondents ratings was also calculated, and afterwards the success factors were ranked by the arithmetic mean of success factors. Calculating the arithmetic mean value on ordinal data is not strictly correct but nevertheless in this case must not be considered as abusing the data too much. The statistics are presented for the total sample in Tables 2(a)-(c) for each success factor. The agreement between the two alternatives is good. The following calculations of the rating of success factors for six different categories of process industry are based exclusively on the arithmetic mean, as otherwise the tables would have been unduly complicated. In Tables 2(a)-(c) for success factors on a tactical level, the numbering of the success factors is supplemented by an asterisk denoting those tactical success factors which have an underlying operational level of success factors.

\section{Research results}

The research results are presented in Tables 2(a)-(c), where the five highest rated success factors, ranked by mean, are shown in bold type and the five next most important in bold italic type, while the five least important success factors are underlined. It is not possible to give a clear definition of what should be called critical success factors, but in this study the ten highest rated success factors have been called critical due to their high relation importance. 
Table 2a Success factors for process development. The 25 potential success factors have been structured on a strategic level for process development. This part of the table presents the 'creating the development project' group. The success factors are numbered in the left column of the table where success factors with underlying operational success factors are marked out with an asterisk. The five top ranked success factors are shown in bold type, while the following five are shown in bold italic type. The lowest ranked are underlined. The results for all respondents are presented in the total column

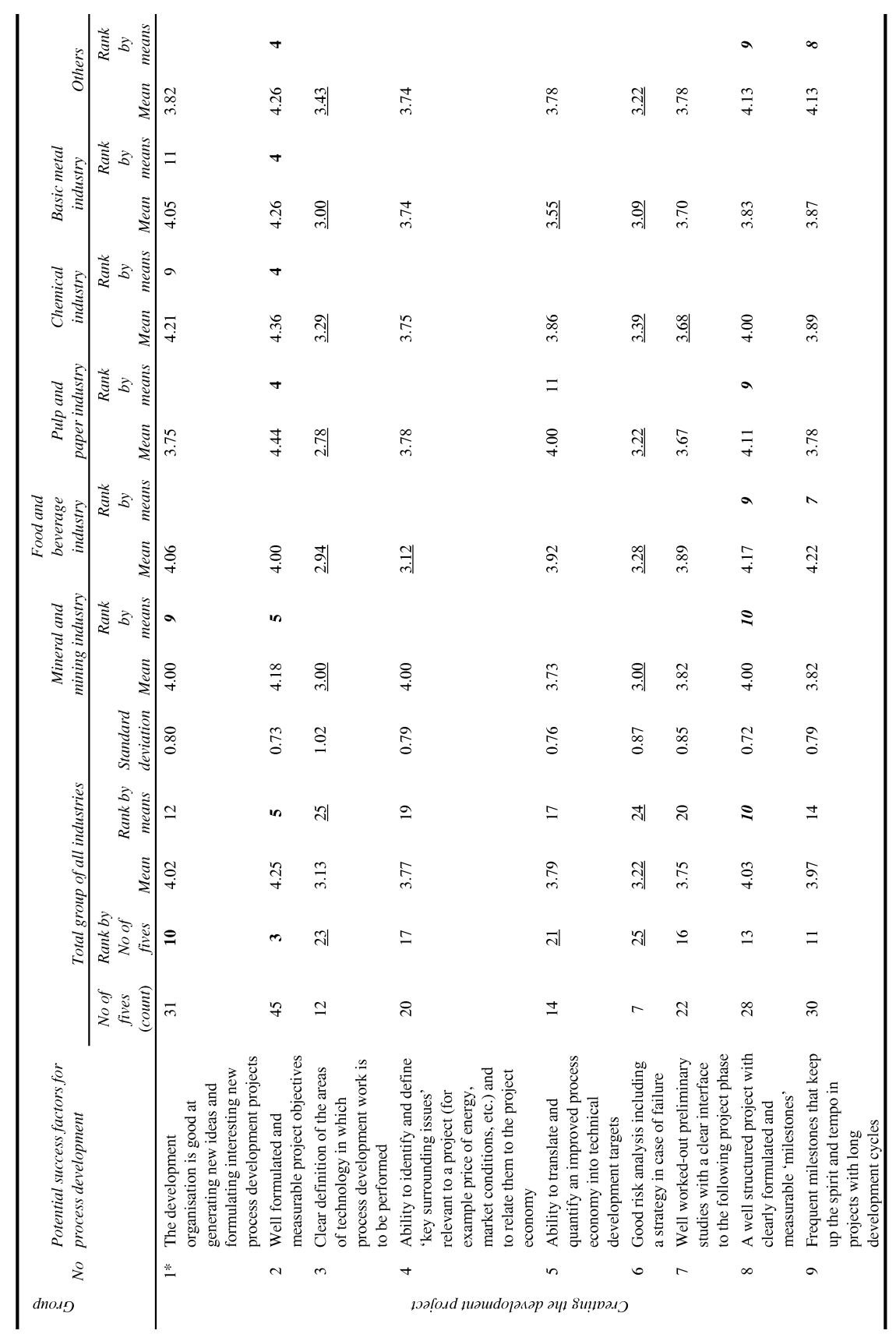


Table 2b Success factors for process development. The 25 potential success factors have been structured on a strategic level for process development. This part of the table presents the 'working on the development project' group. The success factors are numbered in the left column of the table where success factors with underlying operational success factors are marked out with an asterisk. The five top ranked success factors are shown in bold type, while the following five are shown in bold italic type. The lowest ranked are underlined. The results for all respondents are presented in the total column

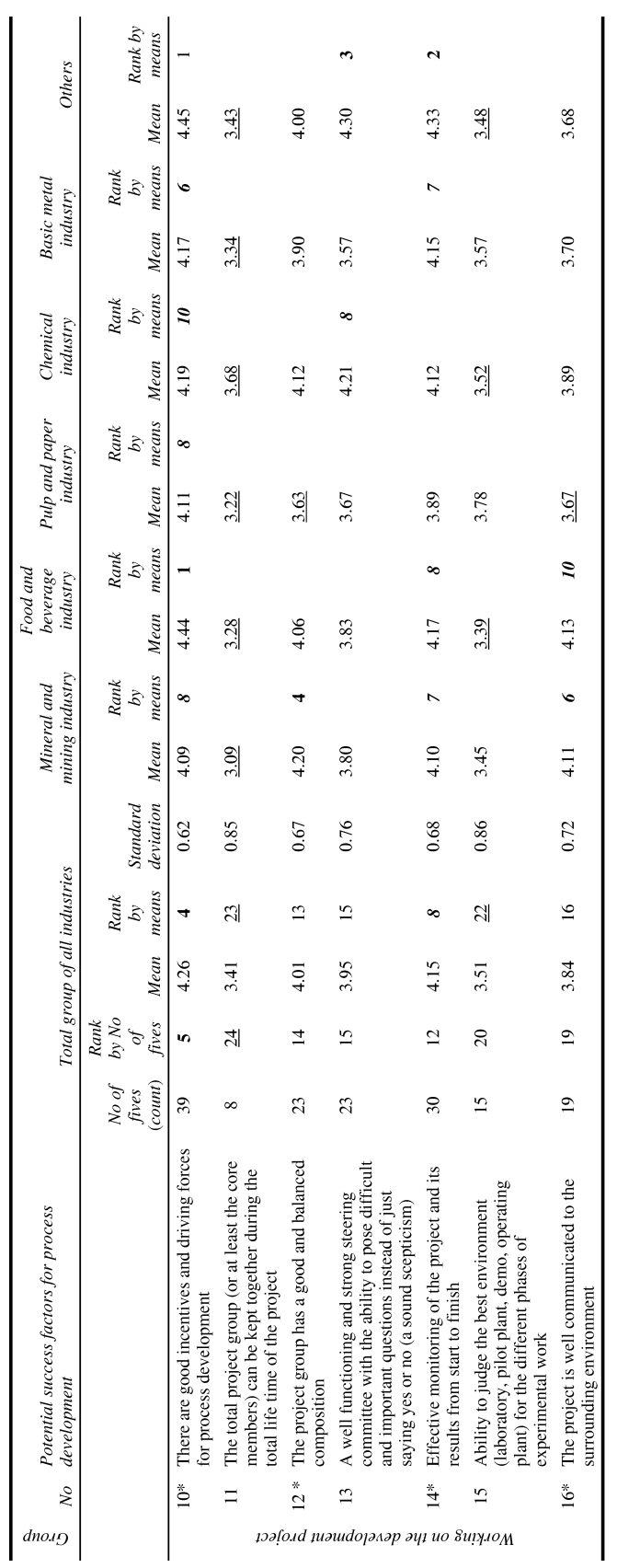


Table 2c Success factors for process development. The 25 potential success factors have been structured on a strategic level for process development. This part of the table presents the 'using the results', 'internal environment' and 'external environment' groups. The success factors are numbered in the left column of the table, where success factors with underlying operational success factors are marked out with an asterisk. The five top ranked success factors are shown in bold type, while the following five are shown in bold italic type. The lowest ranked are underlined. The results for all respondents are presented in the total column

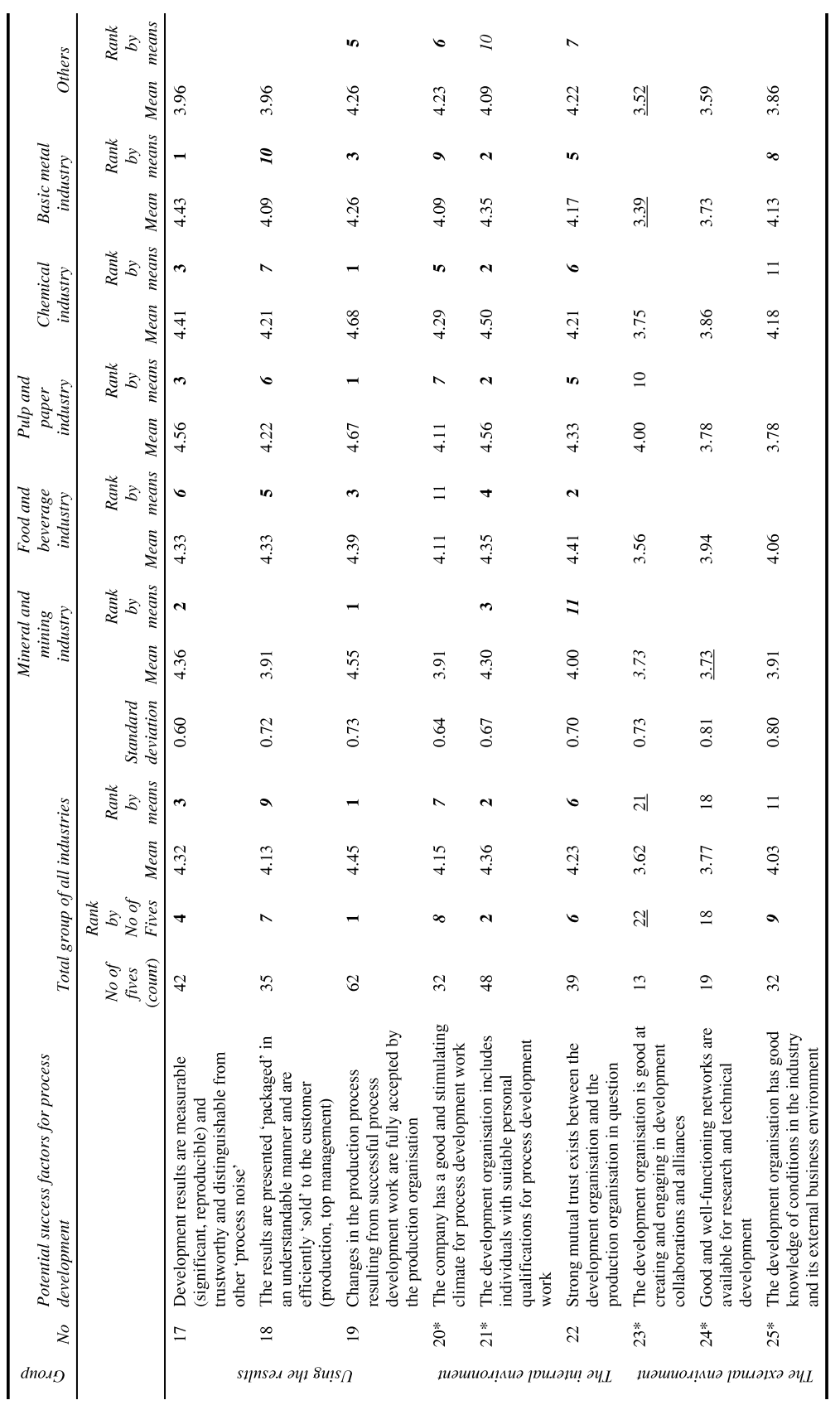




\subsection{Ranking of all individual success factors}

\subsubsection{Most important success factors: the 'top five'}

The five most important success factors for process development were the following, in descending order of importance:

No. 19 Changes in the production process resulting from successful process development work are fully accepted by the production organisation.

No. 21 The development organisation includes individuals with suitable personal qualifications for process development work.

No. 17 Development results are measurable (significant, reproducible) and trustworthy and distinguishable from other 'process noise'.

No. 10 There are good incentives and driving forces for process development.

No. 5 Well formulated and measurable project objectives.

\subsubsection{The five next most important success factors}

The success factors with the next highest scores were:

No. 22 Strong mutual trust exists between the development organisation and the production organisation in question.

No. 20 The company has a good and stimulating climate for process development work.

No. 14 Effective monitoring of the project and its results from start to finish.

No. 18 The results are presented 'packaged' in an understandable manner and are efficiently 'sold' to the customer (production, top management).

No. 8 A well structured project with clearly formulated and measurable 'milestones'.

\subsubsection{The least important success factors: the 'bottom five'}

The five least important success factors for process development were the following, starting with the least important:

No. 3 Clear definition of the areas of technology in which process development work is to be performed.

No. 6 Good risk analysis including a strategy in case of failure.

No. 11 The total project group (or at least the core members) can be kept together during the total life-time of the project.

No. 15 Ability to judge the best environment (laboratory, pilot plant, demo, operating plant) for the different phases of experimental work.

No. 23 The development organisation is good at creating and engaging in development collaborations and alliances. 


\subsection{Comparison of the importance of the five different groups of success factors on a strategic level}

The average ranking point per success factor in each individual group has been calculated for each of the five areas of process development that the success factors were grouped into, and they are presented below in order of ranking:

- $\quad$ using the results (46.3)

- $\quad$ internal environment (39.7)

- $\quad$ creating the development project (23.2)

- $\quad$ working on the development project (22.4)

- $\quad$ external environment (21.3)

The three lowest ranked areas have ranking points that are quite similar, while the two areas 'internal environment for process development' and especially 'using the results from process development' stand out.

\subsection{Comparison of ratings between the six categories of process industry}

There is generally a very good agreement between the six categories of industries. Thus the three least important success factors are rated among the least five important in all six categories. Similarly, the two most important success factors are ranked among the top five by all six categories. One can say that the overall impression of the results is that there is good agreement between different categories of process industry.

\section{Discussion of the research results}

In the development of the list of potential success factors in this study, all success factors that were identified by the respondents during the interviews were included, with the intention of letting the R\&D managers with their ratings be the sole judges. Because of this, some success factors are of a kind that are relevant not only to process development work, but also to other areas of R\&D and even other company functions (as was also pointed out in the questionnaire). Even so, the success factors that were developed in this project can only be regarded as an embryo of a more complete list of success factors for process development in process industry, and it is likely that there are other success factors that should be added to this list. This is also something to be borne in mind by industry professionals insofar as the importance of individual success factors is likely to change over time and some will consequently be removed and others added in the future. In the use of success factors it must also be observed that a high rating of a success factor in an area where the company is currently performing well does not necessarily imply that the company needs to do even better in that area in the future and over-perform - an issue that has been pointed out by Leonard-Barton [25]. 


\subsection{Success factors for different areas of process development}

The potential success factors and the rating of individual success factors is in itself of interest, but the pattern that emerges from the average ranking points for the different groups of success factors is even more interesting. Using results from process development (technology transfer) received by far the highest ranking points.

Sometimes industrial development is likened to a funnel, and it is often argued that there is a need to pour many new ideas into the funnel of the development process to get a few good usable products or processes out of the bottom. This may give the impression that this phase of the development cycle is the most important. It is interesting to note that the results of the present study suggest that the technology transfer phase is very important in the process development process. The conclusion is not of course that there is no need for many good ideas in the beginning, but that we also need to understand how to make the technology transfer more reliable in process development. It must also be observed that technology transfer is not the sole responsibility of the R\&D department; the production department also needs to develop a good receiving capacity for new technology.

In three of the ten top-ranked success factors the theme is trust; the results are 'fully accepted', 'trustworthy results', and 'strong mutual trust'. How do we create a climate of trust for the use of the results? This brings us close to the question of user involvement in process development, a question that was not identified explicitly during the interviews. User involvement is an interesting question that so far has not been given a clear answer, but simplistic treatment of the concept risks leading to unclear results that miss the points of user selection, timing of user involvement, and the user's willingness to be involved, etc. [21].

\subsection{Research results in the context of previous research}

A study by Cooper and Kleinschmidt gives success factors for product development on a company level (about 30\% process industry in the sample), but the selected success factors in their study are more related to product strategy, the market and the product development process [26]. Out of the 72 candidate success factors presented by Balachandra and Friar, success factors for R\&D projects and new product development are strongly market oriented [8]. Lacking previous contributions focusing on success factors for process development, the potential success factors are exploratory results that stand on their own as such. The framework presented by Balachandra and Friar, giving relative importance to different success factors as a consequence of the contextual environment for the R\&D project, agrees with the approach in this study [8]. It is evident that a listing of success factors is of little use by itself unless accompanied by a ranking or rating figure for each individual success factor.

\subsection{Validity and reliability of research results}

The construct validity must be considered high since the respondents are professionals in this area and the questionnaires were properly completed with few question marks or missing data from the respondents. Considering the internal validity and the respondent's ability to correlate the potential success factors to process development success, it is difficult to find more capable respondents for this task. The R\&D managers' ability to 
estimate the correlation between success factors for process development and process development performance must be considered to be high, but their ability to estimate the $R \& D$ department's share in successful process development must be considered lower. The results from the rating of the individual success factors show a surprising similarity between the different categories of process industry. This indicates that the research results are usable in a larger group of industries, and are thus of a more generic nature referring to the previous classification system for success factors. The reliability of the results should not be overrated, and the exact ranking order must not be regarded as totally reliable. The tendencies and the importance of the grouping of the success factors can however be considered more reliable.

The high response rate and share of Swedish process industries gives a high validity for Swedish process industry, but rather poor for European process industry. It could however be argued that geographical location has less influence on success factors for process development than the type of process industry.

\section{Conclusions}

A classification system for success factors has been developed that is proposed to facilitate the further development of success factors for R\&D. A contextual model for the process development process has been developed that can be of use in the further development of success factors for process development as well as in other discussions of the development of process technology. A number of potential success factors for process development have been developed. The importance ratings given to potential success factors for process development have highlighted the area of technology transfer as an important area for successful process development. It is thus not only important to start with a large number of potential ideas in the process development process: it is also important to have a reliable technology transfer process to implement the results from the 'development factory'.

Since there is a good agreement across sectoral borders of the importance of the different success factors, it is thus hypothesised that the findings are valid for process industry in general. The list of success factors for process development is an embryo of a more complete and better list of success factors. Although the top ten success factors can be viewed as critical success factors for companies process development, it is recommended that each company should give its own importance ratings to all success factors, better reflecting its own specific contextual environment.

\section{Acknowledgements}

This work has been partly financed by Kempestiftelserna; their financial support is gratefully acknowledged. Thanks are due to Gunilla Bergdahl for research assistance and help with the survey. Input from discussions with $R \& D$ management staff in process industry is highly appreciated and special thanks are also due to Magnus Tottie of LKAB, who helped with valuable comments and suggestions on the manuscript from an industry perspective. We also sincerely thank all companies who participated in this survey. Thanks to other industry representatives and other persons who substantially helped to improve this paper. 


\section{References}

1 Werner, B.M. and Souder, W.E. (1997) 'Measuring R\&D performance - state of the art', Research Technology Management, March-April, pp.34-42.

2 Robb, W.L. (1991) 'How good is our research?', Research Technology Management, March-April.

3 Brown, M.G. and Svenson, R.A. (1988) 'Measuring R\&D productivity', Research Technology Management, July-August, pp.11-15.

4 Webster's Encyclopedic Unabridged Dictionary of the English Language, Portland House, New York.

5 Lindahl, O. and Lindwall, L. (1978) 'Science and best practice (in Swedish)', Natur och Kultur, Malmö.

6 Sink, S.D. (1985) Productivity Management, John Wiley \& Sons, New York.

7 Griffin, A. and Page, A.L. (1996) 'PDMA success measurement project: recommended measures for product development success and failure', Journal of Product Innovation Management, Vol. 13, No. 6, pp.478-496.

8 Balachandra, R. and Friar, J.H. (1997) 'Factors for success in R\&D projects and new product innovation: a contextual framework', IEEE Transactions on Engineering Management, Vol. 44, No. 3, pp.276-287.

9 Lager, T. and Hörte, S.Å. (2000) 'Critical success factors for improvement and innovation of process technology in process industry', Proceedings of the 3rd International (Euro) CINet Conference, CI 2000: From Improvement to Innovation, September 2000, Aalborg University, Denmark.

10 Day, R.G. (1993) Quality Function Deployment - Linking a Company with its Customers, Quality Press.

11 Griffin, A. and Hauser, J.R. (1991) The Voice of the Customer, Massachusetts Institute of Technology, Working Paper No. 56-91.

12 Nordhaug, O. (1993) Human Capital in Organizations, Scandinavian University Press, Oslo.

13 Cooper, R. (1993) Winning at New Products, Addison-Wesley, Readings.

14 Lager, T. (2000) 'A new conceptual model for the development of process technology in process industry', International Journal of Innovation Management, Vol. 4, No. 3, pp.319-346.

15 von Hippel, E. (1988) The Sources of Innovation, Oxford University Press, Oxford.

16 Hutcheson, P., Pearson, A.W. and Ball, D.F. (1996) 'Sources of technical innovation in the network of companies providing chemical process plant and equipment', Research Policy, No. 25, pp.25-41.

17 Hutcheson, P., Pearson, A.W. and Ball, D.F. (1995) 'Innovation in process plant: a case study of ethylene', Journal of Product Innovation Management, No. 12 pp.415-430.

18 Freeman, C. (1990) 'Technical innovation in the world chemical industry and changes of techno-economic paradigm', in Freeman, C. and Soete, L. (Eds.): New Explorations in the Economics of Technological Change, Printer Publishers, London, pp.74-91.

19 Enos, J.L. (1962) Petroleum Progress and Profits - A History of Process Innovation, The M.I.T. Press, Cambridge.

20 Lee, G. (1993) 'Closing the performance gap through technology transfer: linking theory and practice', International Journal of Technology Management, Vol. 8, Nos. 3-5, pp.236-243.

21 Leonard-Barton, D. and Sinha, D.K. (1993) 'Developer-user interaction and user satisfaction in internal technology transfer', Academy of Management Journal, Vol. 38, No. 5, pp.1125-1139.

22 Knight, K.E. (1984) 'Technology transfer in the petroleum industry', Journal of Technology Transfer, Vol. 8, No. 2, pp.27-34. 
23 Langrish, J. (1971) 'Technology transfer: some British data', R\&D Management, Vol. 1, No. 3, June, pp.133-136.

24 Leonard-Barton, D. (1992) 'The factory as a learning laboratory', Sloan Management Review, Fall, Vol. 34, No. 1, pp.23-38.

25 Leonard-Barton, D. (1995) Wellsprings of Knowledge, Harvard Business School Press.

26 Cooper, R.G. and Kleinschmidt, E.J. (1995) "Benchmarking the firm's critical success factors in new product development', Journal of Product Innovation Management, No. 12, pp.374-391.

27 NACE Rev. 1 (1996) Statistical Classification of Economic Activities in the European Community, Office for Official Publications of the European Communities, Luxembourg.

\title{
Appendix 1: A definition of process development in process industry
}

The following intentional type of definition of process industry characterises this industry in a descriptive manner:

\begin{abstract}
"process industry is production industry using (raw) materials to manufacture non-assembled products in a production process where the (raw) materials are processed in a production plant where different unit operations often take place in a fluid form and the different processes are connected in a continuous flow."
\end{abstract}

Companies are often grouped together in clusters of similar types of industries producing similar types of products and using similar production processes. Using the above definition of process industry, clusters of industries can be selected for an extensional definition of process industry, using the NACE codes for the classification of industries in the European Community [27]. Industries, here proposed to be included in the group process industry, have been selected from the NACE system and clustered as mining and mineral industry, food and beverage industry, pulp and paper industry, chemical industry, basic metal industry, and other process industry. The concept 'development of process technology' has in this study been used synonymously with 'process development'. The concept 'process development' has been chosen as an overall denomination of all types of process development work from process improvement (optimisation) to process innovation (breakthrough or radical process development).

The difference between process development and product development was presented to the respondents in the following way.

"To distinguish between the two terms, 'process development' has in this study been defined as development driven by internal production objectives. Such objectives may be reduction of production costs, higher production yields, improvement of production volumes and product recoveries, environment-friendly production, etc. In many sectors of process industry, process development work is mainly prompted by the needs of production (internal customers). Correspondingly, 'product development' has been defined as development driven by a desire to improve the properties and performance of finished products, even if the nature of the practical development work is process development in a laboratory. Objectives for product development can be improving product properties, improving product quality (uniformity of composition), environment-friendly products, etc." 


\section{Appendix 2: The sample and the survey}

\section{The sample and the sample frame}

The population for this survey can be classed as process industry 'world-wide'. Since it is difficult to get direct access to R\&D organisations, the sample unit is the company. The total sample was 337 companies from European process industry focusing on Swedish industry. For economic reasons, and due to lack of a good sampling frame, the sample was not a simple random sample but consisted of industries selected according to the following criteria:

Type of industry. Process industries were selected according to the previously presented definition. The types of industries were selected using existing statistical codes for European Industry (NACE). Industries from different sectors have been clustered together: mining and mineral industry (NACE codes 13, 14 and 26); food and beverage industry (NACE code 15); pulp and paper industry (NACE code 21); chemical industry - including petrochemical, plastic and rubber but not pharmaceutical (NACE codes 23, 24 and 25); basic metal industry (NACE code 27); other process industry (NACE codes 28, 37, 40, 41 and 24.4 plus some other industries connected to process industry).

Geographical location. For reasons of convenience, most of the companies were selected from Sweden (easy to get in touch with and get information from). The total Swedish sample is 109 companies. A fairly large number of industries from other Nordic countries were also selected (Norway, Finland and Denmark). Total sample of Nordic countries other than Sweden: 80 companies. From the rest of Europe we selected a smaller sample of industries (Germany, the UK, France, the Netherlands, Belgium, Italy, Austria and Switzerland). Total sample of European countries other than Nordic countries: 148.

Size of industry. The firms contacted had at least 200 employees, often more than 500 employees and in many cases much more. Innovation intensity: some parts of the industry sectors presented above were excluded from the sample because of our estimates that the innovation intensity for this group of industries was too low; thus meat production and concrete production, for example, were excluded from the survey.

Conduct of the survey. The questionnaire was sent out to R\&D managers in the respective companies. All questionnaires were sent to a specific person whom we had identified as the right respondent in the organisation. For practical reasons, the method of conducting the survey in Sweden differed from the one used in the rest of Europe. The Swedish survey was carried out according to the following scheme: telephone contact with companies, checking the data and confirming participation - mailing the questionnaire - telefax reminders - telephone reminder - new telephone reminder - final telefax reminder. The scheme for the Nordic and the European survey was: mailing the questionnaire - new mailings after new information (new contact persons or address ) - telefax reminder - final telefax reminder. The questionnaire was presented in Swedish for the Nordic countries and in English for the others. 
Response rate

\begin{tabular}{lccc}
\hline & Sweden & Other Nordic counties & Other European countries \\
\hline Number contacted & 109 & & \\
Number of mailings & 99 & 80 & 148 \\
Number of responses & 78 & 18 & 16 \\
Response rate & $72 \%$ & $23 \%$ & $11 \%$ \\
\hline
\end{tabular}

The response rate is very good for Sweden, considering that the total number of respondents including those who declined to participate on the telephone before the mailing is included in the sample. For some sectors nearly all industries were included in the Swedish sample, making it close to a census for those groups. The response rate dropped dramatically for the rest of the sample because of the different design of the survey. 